\title{
25 Research Square \\ The Effect of Triple-lumen Flushing Training based on the Guideline in the Competence of Nurses
}

\section{Fatemeh Abasi}

Shiraz university of medical sciences

Leila Bazrafkan ( $\square$ bazrafkanl@sums.ac.ir)

Shiraz university of medical sciences

leili mosalanejad

Jahrom University of Medical Sciences

\section{Research Article}

Keywords: Clinical Education, Guideline, Triple-lumen flushing $\square$ Empowerment of nurses, Intensive care

Posted Date: August 18th, 2021

DOI: https://doi.org/10.21203/rs.3.rs-609623/v1

License: (c) (i) This work is licensed under a Creative Commons Attribution 4.0 International License. Read Full License 


\section{Abstract}

\section{Background}

Nurses' clinical education is critical in their empowerment process. Due to the extraordinary sensitivity of special wards, nurse training, especially for novices, appears to be more necessary and critical. The present study aimed at determining how triple-lumen flushing training based on the guideline affected the capacity of nurses in Namazi Hospital's pediatric intensive care unit.

\section{Methods}

The current study was a quasi-experimental pre-test-post-test study conducted in December 2020 until April 2021 on 60 nurses working in the pediatric intensive care units of Namazi Hospital in Shiraz. The samples were counted and divided into two groups of 25 people using the census method. At the beginning of the study, all participants took a pre-test, and then one of the groups was chosen randomly and trained for 10 one-hour sessions based on the revised guidelines of Shiraz University of Medical Sciences professors of Nursing and Cardiology. The training was both theoretical and practical in nature. A four-choice test, a performance checklist, and a valid and reliable attitude questionnaire were used to evaluate the effect of empowerment training in changing the behavior of both intervention and control groups after two weeks. Data were analyzed by SPSS software version 23 using descriptive and inferential statistical methods.

Results

Data analysis revealed a statistically significant difference in knowledge, skills, and attitudes between the intervention and control groups, with a statistically significant coefficient ( $p 0.000)$. There is a positive and significant correlation between nurses' clinical knowledge and their clinical skills $(r=0.290, p=$ 0.041). In other words, nurses' clinical skills have improved in parallel with their clinical knowledge. Furthermore, there is no significant correlation between nurses' attitudes and their level of clinical knowledge $(r=0.066, p=0.650)$. After the intervention, there is no significant correlation between nurses' attitudes and their level of clinical skills $(r=0.030, p=0.836)$.

Conclusion

The current study's findings revealed that the educational intervention of triple-lumen flushing based on the designed guideline has significantly contributed to the excellence and promotion of knowledge, and as a result, the ability of nurses. Developing and implementing guidelines can improve nurses' abilities in specialized areas, particularly in special care.

\section{Background}

Clinical education is one of the most important and decisive components of nursing education, and it plays an important role in shaping nurses' professional identities. Success on this path necessitates the 
adoption of effective approaches that, following current knowledge and in response to new patient needs, provide the necessary preparations in learners [1-3]. Nurses are key members of the health team. Today, along with the development of other sciences, the field of nursing is also developing and evolving. The intensive care unit for children and infants is one of the wards in which nurses play an important role [4]. Nurses spend more time with patients than other caregivers, and their decisions play a very important role in patients' clinical destiny. In this regard, activity in intensive care units is more important than activity in other departments; because nurses must make quick decisions in a short period of time due to the complexity of patients' clinical situations [5].Therefore, one of the most important characteristics of the staff of special wards is strong knowledge and scientific support, and nurses who are not qualified should not be employed [6]. Nurses provide a variety of care to patients admitted to the intensive care unit based on their needs and problems, including respiratory and blood circulation care[7]. One of the most important responsibilities of nurses on special wards is the care of central venous pathways. Improving the quality of central venous catheter care as part of the cardiovascular system requires nurses to perform better by adhering to standard catheter care guidelines. As blood infection is one of the most common causes of nosocomial infections and one of the complications mentioned in venous catheters [8]. Nurses' role in preventing therapeutic complications and achieving the desired therapeutic result is undeniable [9]. In pediatric intensive care units, however, how to teach central venous catheter care is more important. Because of physiological differences in children (high metabolism, increased fluid volume, inability to metabolize drugs, and increased risk of drug side effects), intravenous therapy necessitates more skill and care [10]. Moniz[1] and colleagues in a study entitled "the Incidence rate and use of flushing in preventing peripheral venous catheter occlusion" showed that care time, the complexity of the care process, workload, and the number of nurses are effective in providing care for vascular health and preventing incontinence and infection in patients [11]. Various studies, however, show that nurse training is insufficient to improve their specialized flushing skills, and there is a need to develop guidelines to ensure that these training interventions are based on the best evidence and most up-to-date guidelines [12-14].

Various studies indicate guidelines for central venous catheter care in neonatal intensive care units have been developed [14]. What is certain is that the need to train nursing staff, particularly novice nurses, in all fields, areas of work, and departments are unavoidable and critical. However, given the extreme sensitivity of special departments, training their personnel appears to be more important and vital [15-17]. Because some special skills of special wards such as the triple-lumen flushing guideline are specialized and there is little opportunity for learning during student life, training of central catheter flushing or triple-lumen in graduate nurses is of particular importance. As a result, it can eventually lead to professional performance in graduates and be part of in-service training. Because there was no study on the proper training of triple lumen flushing according to the most recent updated guideline among Iranian nurses, and considering the importance of this skill, Namazi Hospital's pediatricians compiled a guideline which nursing specialists revised according to nursing principles. The present study aimed to determine the effect of triple lumen-flushing training based on the revised guideline on the knowledge, skills, and attitudes of nurses in the pediatric intensive care unit of Namazi Hospital. 


\section{Methods}

\section{Study design, sample, and procedures}

The current study was a quasi-experimental pre-test post-test study with two control and experimental groups that was conducted in the neonatal and pediatric intensive care units of Namazi Hospital in Shiraz in the in December 2020 until April 2021 in. Namazi Hospital is the largest educational medical hospital of Shiraz University of Medical Sciences which has hospital beds and intensive care beds.

\section{Participants}

The study population consisted of all nurses working full-time in the pediatric intensive care unit who entered into the study through a census of 60 nurses from the two pediatric intensive care units. Considering that all the nurses working in the pediatric intensive care unit of Namazi Hospital were women, gender was excluded from the underlying variables leaving only the nurse's age as the underlying variable. The inclusion criteria included being an intensive care nurse (with at least one year of experience in this field) and having an interest and willingness to participate in the study, whereas refusing to continue attending training sessions considered to be an exclusion criterion.

Initially, the purpose of the study was explained to all nurses who met the inclusion criteria and were included in the census, either individually or in groups. Then, a knowledge questionnaire on how to flush triple-lumen was distributed to them, followed by a pre-test. Then all participants were randomly divided into two groups of 25 people.

\section{Instrument}

The triple-lumen flushing guideline is divided into three sections: practical explanation, flushing procedures, and aftercare, which will be briefly explained. Flushing central venous catheters in children result in serious complications and injuries, such as an increased risk of obstruction, embolism, infection, and a reduction in the life of central catheters. Here, in the internal wards of the first and second departments of the Namazi hospital, employing a new technique, a controlled trial is used to perform flushing, blood sampling, and replacement of central venous catheter dressing, which is not performed in any of the hospital wards in the south of the country. This technique increases the central venous catheter's durability, controls infection, and increases the venous catheter's potency.

\section{Guideline teaching and protocol}

Making a standard heparin flushing solution at a rate of 10 units per cc of $0.9 \%$ normal saline solution begins hand washing with the aseptic method. For flushing, a $10 \mathrm{cc}$ syringe is always used because, contrary to popular belief, a $10 \mathrm{cc}$ syringe creates less pressure. More pressure causes the central venous 
catheter to be damaged and ruptured, causing serious damage. The push-pause method is used with a $10 \mathrm{cc}$ syringe and standard solution. Hands are washed first, followed by sterile gloves and a catheter impregnated with a disinfectant solution (chlorhexidine 0.2 percent + alcohol $70 \%$ ). First, one cc of the solution is pushed, followed by a pause, and then another cc pauses and continues. The solution's volume is determined by the size of the central venous catheter. It should be at least twice the volume of the catheter or equal to it. The positive pressure in the push-pause method flushes the particles in the catheter and keeps it from becoming clogged (this method has a significant impact on increasing the life of central catheters, as rapid drug push or flushing reduces the life of the catheter and damages the arteries) the catheter is then clamped.

This checklist was made by the researcher to ensure that the triple-lumen flushing steps are followed correctly. This checklist, which has 10 items and a yes or no answer, was completed by the researcher while observing the work of the studied samples. This checklist also has a score range of 0 to 10 , with higher scores indicating that the steps were completed correctly. The checklist was created using the most recent triple-lumen flushing guide. After making changes, the validity and reliability of this questionnaire were confirmed by face-to-face validity and content validity by nursing education and medical education specialists. To confirm the reliability, a questionnaire was completed by the administrators for ten nurses. Cronbach's alpha coefficient for questionnaires completed by students was equal to 0.85 , which was approved.

The 10-item, multiple choice questionnaire (MCQ) created by the researcher was reviewed. This questionnaire presents the correct basis for performing the triple-lumen flushing technique in the form of four-choice questions and compares them in the form of a pre-test and post-test. The questionnaire's scoring method is as follows: scores 0-3 indicate poor knowledge, scores 4-6 indicate moderate knowledge, and scores 7-10 indicate high knowledge of nurses concerning the triple-lumen technique. After making changes, the validity and reliability of this questionnaire were confirmed by face-to-face validity and content validity by nursing and medical education specialists. A test-retest procedure was used to confirm the reliability of completing the questionnaire. Pearson correlation coefficient of 0.79 and reliability were confirmed for the test in two stages of Baber. The intervention group received 10 sessions of theory training, as well as the presentation of a video and an explanation of the triple-lumen flushing guide in the clinical skills hall of Shiraz School of Nursing, Midwifery, and Medical Sciences. These sessions lasted between 60 and 90 minutes and were held twice a week. One person provided all training based on the guideline, which was reviewed and compiled by professors from the Departments of Nursing and Cardiology (university ICU specialist who is well-versed in all concepts and the triple-lumen guideline). A knowledge post-test was administered to both the intervention and control groups after the theory sessions.

Three questionnaires from different studies were used in this study as the instrument ${ }^{18-20}$. Researchermade attitude questionnaire with 5 questions: This questionnaire is classified as a 5-point Likert from completely disagree (1) to strongly agree (5) score. This questionnaire has a minimum score of 5 and a maximum score of 25 points. The higher the results of this questionnaire, the more positive the attitude 
toward education. After making some changes, nursing education and medical education specialists confirmed the validity and reliability of this questionnaire using face validity and content validity. To confirm the reliability, ten nursing students were asked to complete a questionnaire. Cronbach's alpha coefficient for questionnaires completed by students was equal to 0.81 , and it was approved.

Each nurse in the control group then practiced and repeated the triple-lumen flushing skill on the patient's bed, and this repetition continued until the procedure was correctly performed. This clinical session lasted up to two hours for each nurse and included face-to-face and practical training, supervision, and researcher feedback. A post-test was given to all participants two weeks after each nurse received face-toface training. In addition, the attitude questionnaire was completed by the studied samples, while the performance checklist was completed by the researcher. Nurses' evaluation scores were calculated on a scale of zero to ten to determine their level of clinical knowledge before and after the triple-lumen flushing training course; which means that the minimum and maximum scores that each nurse could obtain from the triple-lumen flushing scale are within this range. The preceding variable is described in light of this. As a result, the results from zero to three indicate that nurses have low levels of clinical knowledge, the results from four to six indicate that nurses have moderate levels of clinical knowledge, and the results from seven to ten indicate that nurses have a high level of knowledge. As a result, the total score of nurses' clinical knowledge prior to and after the training course was calculated on three scales: low, medium, and high. Then, according to the scores obtained from the response of the participants in the range of each of the above three scales, their frequency distribution, and frequency percentage were determined.

\section{Data analysis}

The data were analyzed using descriptive and inferential statistics as well as SPSS version 22 software. The main variables of the study were analyzed using descriptive statistics (mean and standard deviation) and inferential statistics (paired t-test, chi-square). Due to the non-normality of the data after the Kolmogorov-Smirnov test, non-parametric Wilcoxon and Spearman correlation tests were used for analyzing them.

The significance levels in the tests are 0.05 and 0.01 , and the confidence percentages are 95 and $99 \%$, respectively.

\section{Ethics in research}

Participants in this study signed written informed consent and were reminded that they could withdraw from the study at any time, in addition to adhering to the principle of confidentiality. This study has been approved by the University Ethics Committee with the code IR.SUMS.REC.1399.947.

\section{Results}


According to the findings, 60 female nurses working in the pediatric ward of Shiraz Namazi Hospital between the ages of 23 and 39, with an average of 26.72(4.24), took part in this study. The Wilcoxon test results also revealed that there is a significant difference in the level of knowledge of nurses in the intervention or experimental group before and after the training course. (Table 1)

Table 1

Comparison of nurses' knowledge in both the experimental and control groups

\begin{tabular}{|lllll|}
\hline \multicolumn{3}{|c|}{ Experimental $(\mathbf{n = 3 0}$} & Control $(\mathbf{n = 3 0 )}$ & After \\
\hline $\begin{array}{l}\text { Scope of } \\
\text { knowledge }\end{array}$ & $\begin{array}{l}\text { Before } \\
\text { (percentage) }\end{array}$ & $\begin{array}{l}\text { After } \\
\text { (percentage) }\end{array}$ & $\begin{array}{l}\text { Number } \\
\text { (percentage) }\end{array}$ & $\begin{array}{l}\text { Number } \\
\text { (percentage) }\end{array}$ \\
\hline Weak & $42(84)$ & 0 & $45(93.8)$ & $48(96)$ \\
\hline Average & $6(12)$ & 0 & $14(6.2)$ & $4(2)$ \\
\hline Good & $2(4)$ & $50(100)$ & $0(0)$ & $0(0)$ \\
\hline Significance & & $P=0 / 001$ & & $P=0 / 400$ \\
\hline
\end{tabular}

According to the study's second hypothesis, the triple-lumen flushing educational intervention significantly improves nurses' clinical knowledge, attitude and skills. The non-parametric Mann-Whitney $\mathrm{U}$ test results indicate that the average clinical knowledge, attitude and skill of nurses has significantly improved following the educational intervention. (Table 2).

Table 2

The comparison clinical knowledge, attitude and skills mean score of nurses in two groups

\begin{tabular}{|lllll|}
\hline group & Variables & Number & Mean & sig \\
\hline Control & Knowledge & 30 & 25.50 & 0.0001 \\
Intervention & & 30 & 75.50 & \\
Control & Attitude & 30 & 43.68 & 0.014 \\
Intervention & & 30 & 57.32 & \\
\hline Control & skills & 30 & 27.48 & 0.0001 \\
Intervention & & 30 & 73.52 & \\
\hline Test from mann-whitney U test Level of significance $=0.05$ \\
\hline
\end{tabular}

\section{Discussion}


The purpose of this study was to investigate the effect of triple-lumen flushing training based on the revised guideline on the ability of nurses working in Shiraz Namazi Hospital's pediatric wards, the findings of which indicate the need for nurses to participate in triple lumen flushing training programs. The findings indicated the need for nurses to receive the triple-lumen flushing training, and it demonstrated that the implementation of this training program increased nurses' knowledge and skills, resulting in nurses' empowerment. According to the authors' research, there has been no study on the effect of triple-lumen flushing training on empowerment; however, in the case of catheter care in special wards, David et al. (2004) implemented a training program for nurses to reduce catheter site infection, and the results were consistent with our study. According to the findings of their study, an intervention aimed at educating health care providers on the prevention of catheter-associated bloodstream infections may result in a significant reduction in the incidence of primary circulatory infections. Training programs may result in a significant reduction in medical care costs and patient complications, which is attributed to central venous catheterization as part of mandatory training [21]. The results of another study by Bakr et al. (2020) revealed that implementing a training program for nurses would improve their knowledge and practice of caring for patients with head injuries. The study recommended that a regular training program for nurses caring for patients with head injuries be implemented in hospitals, emphasizing the importance of implementing a training program for nurses to reduce the incidence of complications of head injuries[22]. Aloush et al.(2018) conducted another study that found that providing periodic training to nurses working in intensive care units to improve their competence and progress in the workplace is very useful and efficient [23]. One of the most important differences between ICU nurses and other nurses is that intensive care unit nurses are expected to have a wide range of knowledge and understanding of scientific and practical principles. This issue is rarely addressed in nursing education, and as a result, graduates have only a partial and incomplete understanding of their profession. This issue is rarely addressed in nursing education, and as a result, nurses graduate with only a partial and incomplete understanding of their profession. In a way, it is necessary to renew nurses' knowledge and skills every few years. Nursing knowledge should be reviewed every two years, according to nurses, to renew their knowledge and skills at work. Furthermore, the current study's findings are completely aligned with the interprofessional collaboration of physicians in developing guidelines for empowering nurses undergoing intensive care [24-26]. There was a significant association between expertise and clinical skills in this research, as well, and the more knowledge people had, the more clinical skills they had. According to the findings of this study, nurses in intensive care units lack adequate expertise and information about the triple-lumen flushing procedure, and it appears that employing nurses without undergoing intensive care decreases nurses' skills. As a result, even experienced and qualified nurses may need continuing education courses. Continuing education is a method for improving the quality of health care services all over the world, and continuing education programs for doctors and nurses are being implemented in this field [27].

\section{Limitations and future research}


Considering that the findings of this study confirm that clinical nursing education has resulted in increased knowledge and enhanced clinical practice among nurses in special wards; hospitals and centers with special wards could be required to have annual standard training programs in place to design training to improve the level of knowledge, attitude, and practice of nurses working in special wards. In this way, an effective step toward providing standard and correct nursing services and, of course, improving the treatment process can be taken. The findings of this study may be useful to other researchers working in this field. The main limitation of this study was the small statistical population, which was restricted to Shiraz Namazi Hospital's two pediatric wards. Therefore, it is suggested that the findings would be re-studied in a larger volume and at different hospitals to improve the generalizability of the findings and to locate casual data.

\section{Conclusion}

According to the findings of this study, the triple-lumen flushing training course based on the designed guidelines has substantially contributed to the excellence and promotion of knowledge, and as a result, the ability of nurses. Using the findings of this project, it is possible to design a guide for nurses in other specialized intensive care units. And because nurses working in intensive care units are the primary caregivers of venous lines and airway maintenance for patients, their specialized training with the cooperation of physicians and nurses is beneficial. Inadequate information and an inappropriate attitude cause nurses to perform poorly, limiting their capacity to effectively and appropriately care for the patient and her intravenous access. As a result, training nurses to be aware of standard practice guidelines in the field of proper tool use to avoid complications and injuries caused by them is necessary and vital training.

\section{Declarations}

\section{Ethics approval and consent to participate}

This study was conducted in accordance with the World Medical Association's Declaration of Helsinki. To comply with ethical considerations, research permission was obtained from the Ethics Committee of Shiraz University of Medical Sciences (ethics code: IR.SUMS.REC.1399.947). Also, by providing participants with information about the objectives of the research and obtaining permission to record audio, they also were assured that the information gathered would remain confidential; then "informed consent was provided by all the participants " They were also told that they could leave the study whenever they wanted.

\section{Consent for publication}

Not applicable. 


\section{Competing interests}

The authors declare no conflict of interest.

\section{Availability of data and materials:}

The confidentiality of the identity of the participants. Data are however available from the authors upon reasonable datasets generated and analyzed during the current study are not publicly available due to request. The datasets generated and/or analyzed during the current study are available in the $\mathrm{Dr}$ L.Bazrafkan repository by call N. 0917704288 or Email bazrafcan@gmail.com

\section{Funding}

The present article was extracted from a thesis written by Fatemeh Abasi. The design and implementation of the project was financially supported by Shiraz University of Medical Sciences, Shiraz, Iran. The role of the funding body in the design and implantation of the study (Grant No. 21499-01-0199).

\section{Authors' contributions}

LB contributed to the study design, Contributed to the data analysis, wrote the main manuscript text. FA Contributed to the data acquisition. Study design, and wrote the main manuscript text and Lm contributed to the study design, revised the manuscript. All authors read and approved the final manuscript.

\section{Acknowledgements}

We thank all participants who have been involved and contributed to the procedure of data collection.

\section{References}

1. Jayasekara R, Smith C, Hall C, Rankin E, Smith M, Visvanathan V, Friebe TR. The effectiveness of clinical education models for undergraduate nursing programs: A systematic review. Nurse education in practice. 2018 Mar 1;29:116-26. doi. 10.1016/j.nepr.2017.12.006.

2. Kim SO, Choi YJ. Nursing competency and educational needs for clinical practice of Korean nurses. Nurse education in practice. 2019 Jan 1;34:43-7. doi. 10.1016/j.nepr.2018.11.002

3. Bazrafkan L, Najafi Kalyani M. Nursing Students' Experiences of Clinical Education: A Qualitative Study. Investigacion y educacion en enfermeria. 2018 .Dec;36(3). doi. 10.17533/udea.iee.v36n3e04 
4. Razieh S, Somayeh G, Fariba H. Effects of reflection on clinical decision-making of intensive care unit nurses. Nurse education today. 2018 Jul 1;66:10-4. doi: 10.1016/j.nedt.2018.03.009

5. Gopalan PD, Pershad S. Decision-making in ICU-a systematic review of factors considered important by ICU clinician decision makers with regard to ICU triage decisions. Journal of critical care. 2019 Apr 1;50:99-110. doi. 10.1016/j.jcrc.2018.11.027

6. Pishgooie AH, Barkhordari-Sharifabad M, Atashzadeh-Shoorideh F, Falcó-Pegueroles A. Ethical conflict among nurses working in the intensive care units. Nursing ethics. 2019 Nov;26(7-8):222538. doi. $10.1177 / 0969733018796686$.

7. Khatiban M, Gomarverdi Sh, Bikmoradi M, Soltanian AR. The Effect of Education on Impediments perception of Adherence from Infection Control Standards in Intensive Care Nurses: A Randomized Clinical Trial. Scientific Journal of Hamadan Nursing \& Midwifery Faculty. 2014; 22(2): 76-82.doi : 10.29252/psj.18.1.49

8. Azarfarin R, Mohammadziae Totonchi A, Rostami M , Bakhshandeh H, Servati F, Kooshki F. Comparative study of the effect of clinically-indicated replacement and routine replacement of peripheral venous catheters on catheter-related complications and satisfaction in patients undergoing cardiac surgery. Cardiovascular Nursing Journal. 2018; 7(1): 34-41.

9. Aliakbari F, Haghani F. Patient's Bedside Teaching: Advantages and Disadvantages. Iranian Journal of Medical Education.2010; 5 (10): 7-16.

10. Khoeiniha F, Sheikhi MR, Shokati AM, Mohammad Poor A .Nurses' clinical performance assessment in critical care units in teaching and non-teaching hospitals in Qazvin city: Based on Synergy Model.2015. Health promotion management J.2016; 5(3): 23-34.

11. Muniz Braga L, dos Santos Dinis Parreira PM, Arreguy-Sena C, Carlos DM, dos Santos Mendes Mónico L, Pereira Henriques MA. Incidence rate and the use of flushing in the prevention of obstraction s of the peripheral venous catheter . Texto \& Contexto Enfermagem. 2018 Oct 1;27(4). doi.org/10.1590/0104-07072018002810017

12. David K Warren 1, Jeanne E Zack, Jennie L Mayfield, Alexander Chen, Donna Prentice, Victoria J Fraser, Marin H Kollef. The effect of an education program on the incidence of central venous catheter-associated bloodstream infection in a medical ICU. Chest Jour. 2004; 126(5):1612-8. DOI: $10.1378 /$ chest.126.5.1612

1. O'grady NP, Alexander M, Burns LA, Dellinger EP, Garland J, Heard SO, Lipsett PA, Masur H, Mermel LA, Pearson ML, Raad II. Guidelines for the prevention of intravascular catheter-related infections. Clinical infectious diseases. 2011 May 1;52(9):e162-93. doi. 10.1093/cid/cir257

2. Loveday HP, Wilson JA, Pratt RJ, Golsorkhi M, Tingle A, Bak A, Browne J, Prieto J, Wilcox M. epic3: national evidence-based guidelines for preventing healthcare-associated infections in NHS hospitals in England. Journal of Hospital Infection. 2014 Jan 1;86:S1-70. doi. 10.1016/S0195-6701(13)600122

Page $11 / 13$ 
3. Salm F, Schwab F, Geffers C, Gastmeier P, Piening B. The implementation of an evidence-based bundle for bloodstream infections in Neonatal Intensive Care Units in Germany: a controlled intervention study to improve patient safety. infection control \& hospital epidemiology. 2016 Jul;37(7):798-804. DOI: 10.1017/ice.2016.72

4. Karabay M, Kaya G, Hafizoglu T, Karabay O. Effect of camera monitoring and feedback along with training on hospital infection rate in a neonatal intensive care unit. Annals of clinical microbiology and antimicrobials. 2019 Dec;18(1):1-6. doi. 10.1186/s12941-019-0332

17. Taylor JE, McDonald SJ, Earnest A, Buttery J, Fusinato B, Hovenden S, Wallace A, Tan K. A quality improvement initiative to reduce central line infection in neonates using checklists. European journal of pediatrics. 2017 May;176(5):639-46. DOI: 10.1007/s00431-017-2888-x

18. Rosati P, Saulle R, Amato L, Mitrova Z, Crocoli A, Brancaccio M, Ciliento G, Alessandri V, Piersigilli F, Nunziata J, Cecchetti C. Mindful organizing as a healthcare strategy to decrease catheter-associated infections in neonatal and pediatric intensive care units. A systematic review and grading recommendations (GRADE) system. The Journal of Vascular Access. 2021 Feb doi: $10.1177 / 1129729821990215$

19. Leistner R, Thürnagel S, Schwab F, Piening B, Gastmeier P, Geffers C. The impact of staffing on central venous catheter-associated bloodstream infections in preterm neonates-results of nationwide cohort study in Germany. Antimicrobial resistance and infection control. 2013 Dec;2(1):1-6. DOlhttps://doi.org/10.1186/2047-2994-2-11

20. Taylor JE, McDonald SJ, Earnest A, Buttery J, Fusinato B, Hovenden S, Wallace A, Tan K. A quality improvement initiative to reduce central line infection in neonates using checklists. European journal of pediatrics. 2017 May;176(5):639-46. DOI: 10.1007/s00431-017-2888-x

21. David K Warren ${ }^{1}$, Jeanne E Zack, Jennie L Mayfield, Alexander Chen, Donna Prentice, Victoria J Fraser, Marin H Kollef. The effect of an education program on the incidence of central venous catheter-associated bloodstream infection in a medical ICU. Chest Jour. 2004; 126(5):1612-8. doi. 10.1378/ chest.126.5.1612.

22. Bakr A, Shehab MS, El-Zayat RN. Assessment of nurses' performance regarding care of patients undergoing crdiac catheterization . Port Said Scientific Journal of Nursing. 2020 Jun 30;7(2):57-77. DOI: 10.21608/PSSJN.2020.94763

23. Aloush SM, Alsaraireh FA. Nurses' compliance with central line associated blood stream infection prevention guidelines. Saudi medical journal. 2018 Mar;39(3):273. doi. 10.15537/smj.2018.3.21497

24. Hojat M. Need Assessment of Nursing Personnel of Jahrom University of Medical Sciences Using Delphi Technique in 2008. Iranian Journal of education in medical sciences.2010; 10(4).464-473.

25. Ameryoun A, Chaghary M, Tofighi Sh. The study of hospital accreditation procedure in selected countries and presentation of guidelines for IRAN. I J Teb va tazkieh.2013; 8 (61)1-22.

26. Irajpour A, Farzi S, Saghaei M, Ravaghi H. Effect of interprofessional education of medication safety program on the medication error of physicians and nurses in the intensive care units. Journal of 
education and health promotion. 2019;8. doi: 10.4103/jehp.jehp_200_19

27. Mahdizadeh AH, Taheri Z. Educational needs assessment of nurses working in hospitals of Tehran University. Journal of nursing education. 2016 Oct 15;5(3):1-9.dio :10.21859/jne-05031 